\section{Down and out in Murray Hill}

The name Bell Labs is a byword for technological creativity. But its future is now clouded by the financial woes of its parent company, Lucent Technologies. Irwin Goodwin reports.

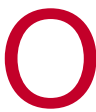
$\mathrm{f}$ all the world's industrial research centres, Bell Laboratories wears the crown. Bell Labs has been an icon of ingenuity ever since its launch in 1925 by American Telephone \& Telegraph (AT\&T). At their base in Murray Hill, New Jersey, Bell Labs' researchers pioneered the development of transistors, lasers, optics, digital data transmission, satellite communications and the UNIX computer operating system. Over the years, the labs' work has been honoured with an astonishing six Nobel prizes.

For anyone fascinated by the interface between fundamental physics and high technology, therefore, Bell Labs' present circumstances are a cause for serious concern. The current economic slump has hit all high-tech firms hard. But a series of disastrous business decisions, and a high-profile failed merger, have placed Bell Labs' parent, Lucent Technologies, in especially dire straits. Late last month, recording net losses of $\$ 3.2$ billion for the second quarter of 2001 , the company announced a restructuring that will see $15,000-20,000$ jobs cut from its

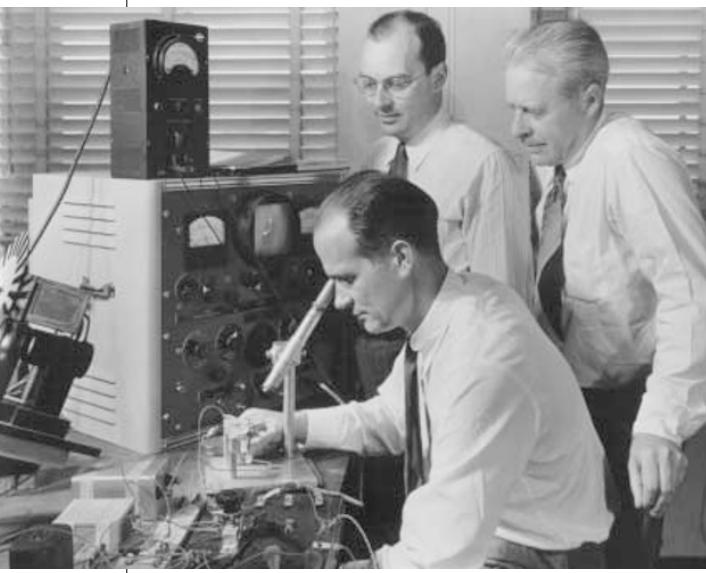

Transistor inventors: William Shockley (seated), Walter Brattain (right) and John Bardeen.

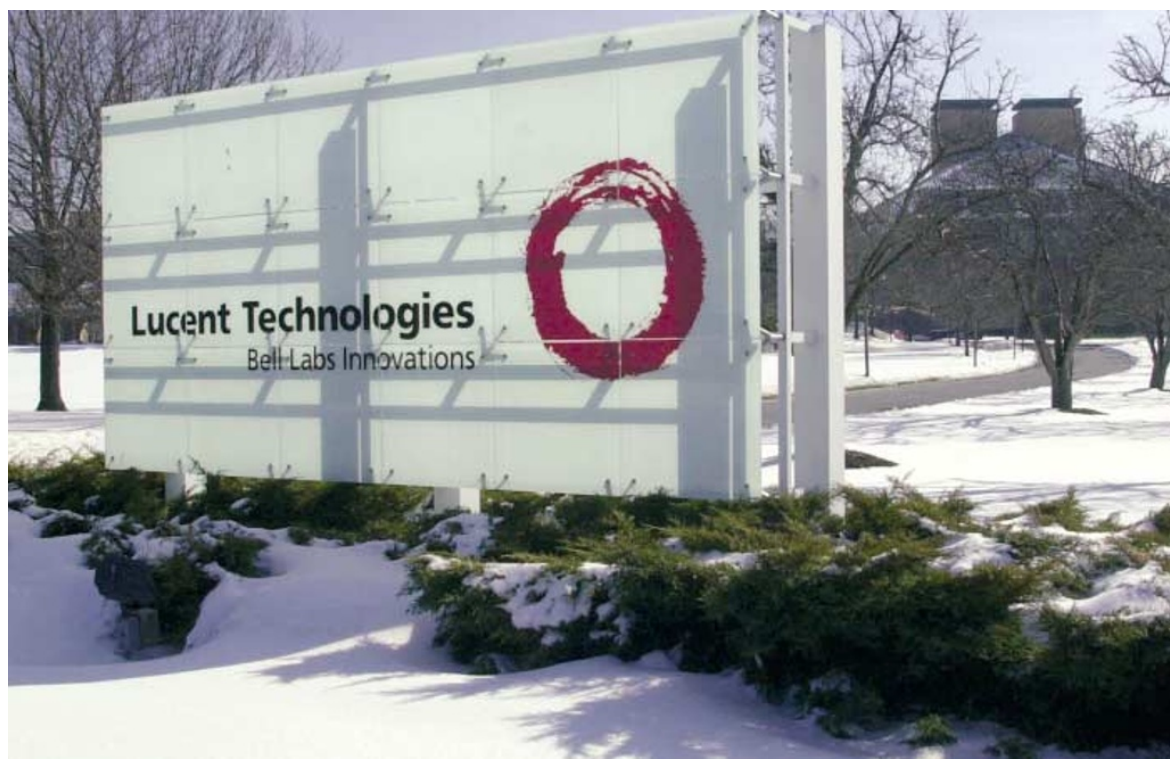

current worldwide workforce of 76,000 - in addition to the 19,000 positions shed since the start of the year.

Bell Labs' managers are confident that its scientists, mathematicians, engineers and technicians - some 3,000 of whom are engaged in research, rather than product development — will be protected from the worst of the looming cuts. But as everyone associated with Lucent is forced to tighten their belts, morale is slipping, particularly among researchers who have never known the harsh reality of life in a struggling company. "What is happening here at Bell Labs is an entirely new experience for many young scientists," says one veteran of the labs.

\section{Practically perfect}

Speak to some of Bell Labs' best-known alumni and the sense of tragedy becomes all the more tangible. Steve Chu of Stanford University in California, who shared the 1997 Nobel Prize in Physics for developing techniques to cool and trap atoms using lasers, joined the labs in 1978. "We felt like

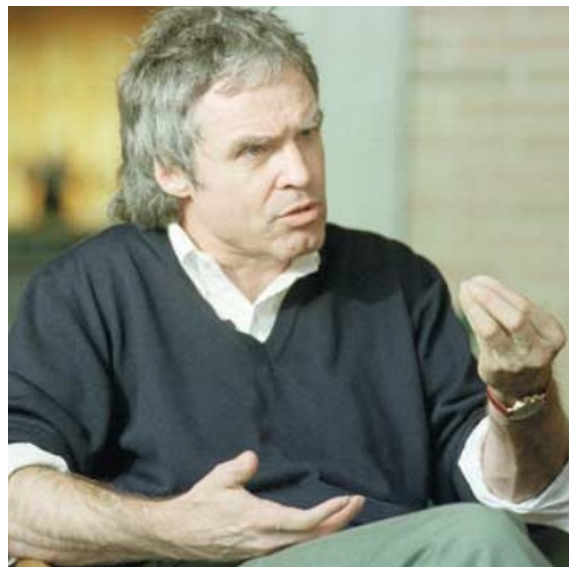

Bell Nobel: Horst Störmer, one of the labs' laureates, was optimistic when Lucent took over. the Chosen Ones," he recalls. "The joy and excitement of doing science permeated the halls, and the cramped labs and offices forced us to interact with each other. Management supplied us with funding, shielded us from extraneous bureaucracy and urged us not to be satisfied with doing merely 'good' science. Life at Bell Labs was practically perfect."

In this idyllic environment, research flourished - and despite Lucent's financial plight, Bell Labs' scientists are still at the forefront of technological innovation. Current projects include the development of 'electronic paper', portable sheets that can be 'reprinted' at the touch of a button to display different documents (J. A. Rogers et al. Proc. Natl Acad. Sci. USA 98, 4835-4840; 2001). And in March, a Bell Labs team reported the discovery of superconductivity in a plastic material (J. H. Schön et al. Nature 410, 189-192;2001).

So what went wrong? Many researchers say that the current uncertainty can be traced back to the mid-1990s, when a government

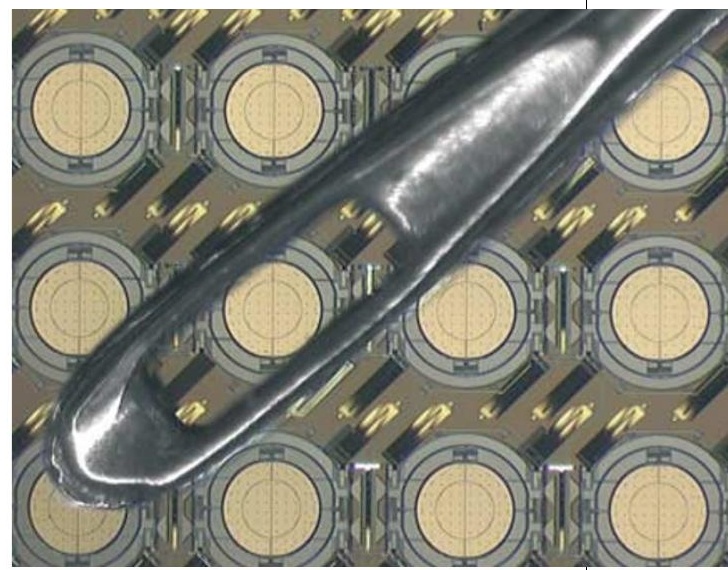

Needle's eye: these Bell Labs' micromirrors route data by reflecting light between optical fibres. 
antitrust investigation into AT\&T was in full swing. "In 1995, the year AT\&T was being pummelled in the press and the courts as a monopoly, the mood was about as black as can be," says Jim Eisenstein, a condensedmatter physicist at the California Institute of Technology in Pasadena, who was at Bell Labs for six years in the early 1990s. "We didn't know if we would be working there in a month or two."

But when AT\&T was ordered to spin off its systems and technology division in 1996, and the majority of Bell Labs' activities came under the new company, Lucent Technologies, many researchers were optimistic. Horst Störmer spent 23 years at the labs, the last nine as director of physical research, until leaving in 1999 to teach at Columbia University in New York. "Under AT\&T, we were considered a bunch of nerds, who might or might not come up with products. We thought Lucent would be technologically driven and run by techies," says Störmer, who shared the 1998 physics Nobel for discovering that electrons acting together in strong magnetic fields can form 'quasi-particles' with charges that are fractions of a single electron's. "Our job was to demonstrate that the company could be scientifically vibrant."

\section{Dimmed outlook}

But life under Lucent turned out not to be so rosy. The company took over Bell Labs' research activity on a much smaller turnover than that enjoyed by AT\&T - which in hindsight was always going to be difficult to sustain. Industry analysts add that Lucent failed to reverse AT\&T's tendency to be slow in turning Bell Labs' bright ideas into marketable technologies. In the late 1990s, for instance, Lucent decided not to push the development of a new generation of optical networking equipment. To the dismay of Bell Labs' scientists, Canada's Nortel Networks, Lucent's principal rival in this field, pressed ahead with the technology, and today its share of the optical networking market is several times that of Lucent.

"This industry is about great products," says Vinod Khosla of Kleiner, Perkins, Caufield \& Byers, a venture-capital firm in Menlo Park, California. "And for a long time, Lucent has been coasting on older products."

But this alone does not explain Lucent's current difficulties. Even Nortel is now struggling, as the world's optical networks have more capacity than is needed. Lucent's particular problems stem in large part from a strategy that ran spectacularly into the buffers when the high-tech stockmarket bubble burst last year.

"Things went bad when the managers bet on the wrong horses," says Eisenstein. Lucent had concentrated on providing infrastructure for the new Internet economy. The company had also aggressively acquired about a dozen start-up dotcoms, and loaned money,

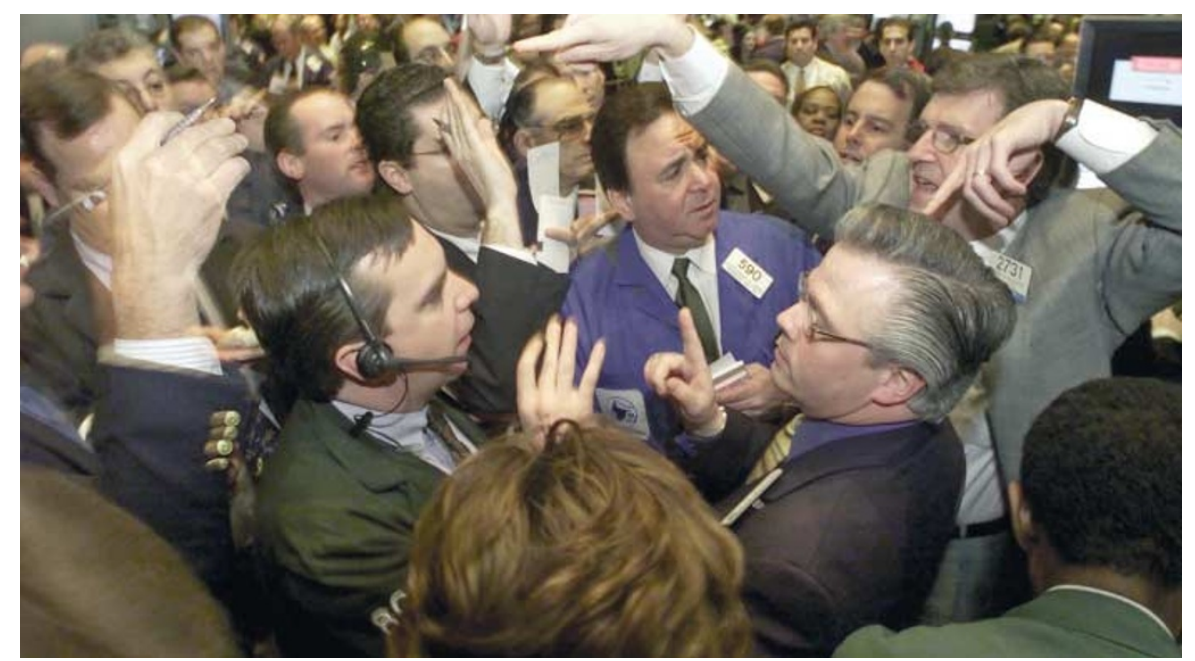

Signs of the times: trading in Lucent shares at the New York Stock Exchange in April.

products and services to its customers.

When the crash came, Lucent was disastrously exposed - as is illustrated by two recent losses. The company was building a fibre-optics network for One.Tel, an Australian media firm that collapsed in May. Lucent claims to have lost at least $\$ 488$ million on this deal alone. Winstar Communications, another major customer, filed for bankruptcy protection in April, owing Lucent some $\$ 700$ million.

The failure in May of a proposed merger with the French telecoms company Alcatel deepened the gloom and further diminished Lucent's sliding stock-market valuation. Now Lucent is restructuring in a bid to rescue its finances. The company's fibre-optics operations have already been sold for $\$ 2.75$ billion. Lucent is spinning off its voice and data network business into a company called Ayava and its activities in microelectronics into a firm called Agere. These companies are taking with them only a small percentage of Bell Labs' fundamental research scientists but their loss will be felt. "We will lose some of the synergism that enabled people to bounce ideas off scientists in other fields," laments one Bell Labs researcher.

\section{No surrender}

Senior managers are putting a brave face on the current situation. "We have every intention of staying in the game and continuing to contribute world-class research," says Bell Labs' vice-president, William Brinkman. He points to the high calibre of scientists such as John Rogers, director of condensed-matter physics, who is heading the electronic-paper project, and applied mathematician Wim Sweldens, head of scientific computing research.

"I'm impressed with those joining us now," adds Brinkman. "They're not the sort who want to strike it rich with stock options. They want to publish their discoveries. They want the opportunity to mix with engineers, mathematicians and the variety of physical scientists here to develop new devices."

But as Lucent's problems deepen, few young scientists are joining Bell Labs. Last year, the labs hired 20 newly graduated physicists and mathematicians, but so far this year only a handful of postdocs have been taken on. Many Bell Labs scientists, meanwhile, are quietly making it known that they are in the market for alternative employment. "We have been enriched by recruiting some of the very best and brightest," says Hans Coufal, manager of science and technology research at IBM's Almaden Research Center in San Jose, California.

When Nature visited Bell Labs' headquarters just days before the announcement of Lucent's latest financial results, Brinkman was confident that the spirit of innovation at the labs would help Lucent bounce back. Although Bell Labs' total workforce might be reduced by $25 \%$, he anticipated no forced redundancies in basic research.

But a tour of the labs showed that costcutting is rampant. Fluorescent lights have been removed from hallways, staff have been asked to hand back cellphones, and those working late can no longer order pizza on Lucent's tab. A memo circulated a few weeks ago summed up the situation: "If every employee spent $\$ 5$ less per month on telephone calls at work, we could save the company up to $\$ 4$ million annually."

Phones and pizza are not the real issues, of course - the main concern is whether the labs' tradition of allowing researchers the freedom to explore the areas they find interesting can survive.

Nevertheless, many staff remain loyally optimistic. "I believe these hard times will force us to come up with even better ideas," says mathematician Jelena Kovacevic. "This place will be preserved, I'm sure.” Physicists and aficionados of high technology are crossing their fingers and hoping she's right.

Irwin Goodwin is a freelance writer in Washington.

http://www.bell-labs.com

http://www.lucent.com 